\title{
A PRESENÇA DE ANTONIO FAGUNDES NA CENA TEATRAL BRASILEIRA
}

\section{THE PRESENCE OF ANTONIO FAGUNDES AT THE BRAZILIAN THEATER SCENE}

\author{
Rodrigo Francisco Dias* \\ Instituto Federal de Minas Gerais - IFMG \\ dias.rodrigof@gmail.com
}

A historiadora e professora Rosangela Patriota possui uma trajetória de destaque no âmbito da historiografia do Teatro Brasileiro. Desde 1995, quando a autora concluiu a sua Tese de Doutorado intitulada Fragmentos de Utopias: Oduvaldo Vianna Filho - um dramaturgo lançado no coração de seu tempo, ${ }^{1}$ até o presente momento, Rosangela Patriota vem dando significativas contribuições para a escrita da História do Teatro Brasileiro por meio de pesquisas que resultaram em obras como A crítica de um teatro crítico, ${ }^{2}$ História e Teatro: discussões para o tempo presente ${ }^{3}$ e Teatro Brasileiro: ideias de uma história, este último, diga-se de passagem, escrito a quatro mãos em parceria com o crítico, ensaísta, professor e editor Jacó Guinsburg. ${ }^{4}$

* Doutor em História pela Universidade Federal de Uberlândia. Professor do Ensino Básico, Técnico e Tecnológico do Instituto Federal de Educação, Ciência e Tecnologia de Minas Gerais (IFMG Campus Bambuí). Integrante do Núcleo de Estudos em História Social da Arte e da Cultura (NEHAC/UFU).

1 A referida tese foi, posteriormente, publicada sob a forma de livro. Ver: PATRIOTA, Rosangela. Vianinha: um dramaturgo no coração de seu tempo. São Paulo: Hucitec, 1999. 232p.

2 PATRIOTA, Rosangela. A crítica de um teatro crítico. São Paulo: Perspectiva, 2007. 240p.

3 PATRIOTA, Rosangela. História e Teatro: discussões para o tempo presente. São Paulo: Edições Verona, 2013. 202p.

4 PATRIOTA, Rosangela; GUINSBURG, Jacó: Teatro Brasileiro: ideias de uma história. São Paulo: Perspectiva, 2012. 269p. 
Para além de tais trabalhos, Rosangela Patriota produziu uma série de artigos acadêmicos, capítulos de livros, ensaios e palestras, bem como atuou na organização de diversas coletâneas, geralmente abordando não só as relações da História com o Teatro, mas também com as linguagens artísticas em uma perspectiva mais abrangente. Se tivermos em vista toda essa vasta produção intelectual da pesquisadora e se igualmente levarmos em conta que a mesma também orientou uma série de monografias, dissertações de mestrado e teses de doutorado de outros pesquisadores, não é exagero nenhum afirmarmos que, por todo o seu percurso acadêmico, o trabalho de Rosangela Patriota pode ser descrito, sem sombra de dúvidas, como um dos mais profícuos dentro da historiografia do Teatro Brasileiro.

Diante dessas breves considerações iniciais, o leitor mais desavisado poderia se indagar: que interesse uma pesquisadora com o perfil de Rosangela Patriota teria na trajetória de um artista como Antonio Fagundes? Afinal, no senso comum, Fagundes é um sujeito ligado à cultura de massas, sobretudo ao campo da televisão e do cinema. Por que Rosangela Patriota se dedicaria a passar vários anos de sua vida pesquisando a trajetória intelectual, artística e profissional de alguém como Antonio Fagundes? Pois foi justamente essa pesquisa que Patriota fez nos últimos anos, um árduo trabalho cujo resultado pode ser visto nas páginas do recém-lançado livro Antonio Fagundes no palco da história: um ator, publicado em 2018 pela Editora Perspectiva. ${ }^{5}$

Trata-se, de fato, de uma obra de peso, e dizemos isso não somente em razão das quase 500 páginas do livro. As inúmeras informações e reflexões presentes em Antonio Fagundes no palco da história: um ator contribuem para que a narrativa elaborada por Rosangela Patriota seja bastante densa. A autora se vale de seu amplo conhecimento bibliográfico sobre as artes cênicas no Brasil e também de depoimentos, cartas, fotografias, críticas de jornais e vários outros documentos para compor um panorama da trajetória do ator, produtor e intelectual Antonio Fagundes com foco em seu trabalho no teatro. Acreditamos, aliás, que este talvez seja um dos principais objetivos do livro: colocar em evidência o fato de Fagundes ser um homem de teatro, para além dos seus conhecidos trabalhos na televisão e no cinema.

De acordo com Rosangela Patriota, a trajetória de Antonio Fagundes

PATRIOTA, Rosangela. Antonio Fagundes no palco da história: um ator. São Paulo: Perspectiva, 2018. 488p. 


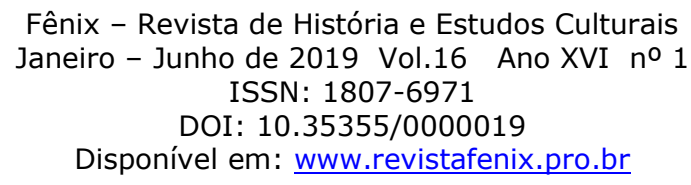

deve ser vista, interpretada e compreendida à luz das circunstâncias históricas e sociais que a acolheram. Sob essa óptica, Fagundes é um personagem fascinante, na medida em que construiu suas experiências em meio a debates e tensões possíveis de serem analisadas, sob horizontes de expectativas diferentes ou, em outras palavras: é sabido que o tempo não é apreendido da mesma forma por sujeitos e esferas sociais distintos, isto é, as rupturas vistas e sentidas, por exemplo, no campo da política não se apresentam necessariamente nos mesmos termos na esfera cultural, assim como os ditames e os ritmos da ordem econômica muitas vezes são sentidos e definidos sob regime e expectativas próprias. No que se refere à história do Brasil recente, de forma geral, localizamos o rememorar, seja como experiência, seja como memória histórica, em marcos construídos a partir de acontecimentos políticos e/ou econômicos. Por exemplo, é comum localizarmos interpretações que se organizam da seguinte maneira: antes do Golpe de 1964; com a instauração da ditadura militar; período do milagre econômico; Plano Cruzado; Plano Real; Nova República; Era Collor; período do AI-5; período da luta armada etc. Nesse sentido, há uma temporalidade que organiza as narrativas a partir de instâncias eleitas e, com isso, busca-se, por meio dessas lentes, apreender outras dinâmicas da vida social [...] Provavelmente, é isso que ocorre quando pensamos a cultura e a arte como simples desdobramentos dos processos políticos e econômicos. É claro, isso não significa dizer que eles não são importantes, nem que não gerem impactos sobre as demais esferas sociais. Contudo, não perceber como as instâncias que compõem uma sociedade possuem dinâmicas específicas, ao mesmo tempo que se articulam com as demais, muitas vezes nos expõe a fragilidades que acabam sendo incorporadas às nossas interpretações. ${ }^{6}$

Com base nessas palavras da autora, podemos entender quais foram os caminhos metodológicos que orientaram a escrita do livro. Para Rosangela Patriota, a vida e a obra de Antonio Fagundes não devem ser entendidas como um mero reflexo das circunstâncias históricas e sociais mais amplas. Do ponto de vista da autora, e isso fica mais claro à medida em que se lê todo o livro, há como que um jogo entre o indivíduo - Antonio Fagundes - e o processo histórico, onde o sujeito se posiciona constantemente de maneira ativa diante das circunstâncias externas a ele. É por isso que Patriota afirma que "o tempo não é apreendido da mesma forma por sujeitos e esferas sociais distintos".

Tal postura teórico-metodológica da autora pode ser percebida no modo como Patriota analisa a trajetória de Antonio Fagundes nos palcos brasileiros desde os anos iniciais, quando o ator travou o seu primeiro contato com o teatro no colégio Rio

6 PATRIOTA, Rosangela. Antonio Fagundes no palco da história: um ator. São Paulo: Perspectiva, 2018, p. 52-53. 


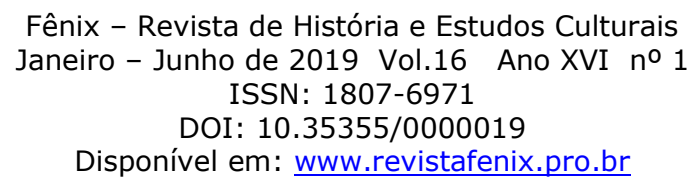

Branco, em São Paulo (SP), por meio da encenação de A Ceia dos Cardeais (de Júlio Dantas, 1902), até o período mais recente, no qual Fagundes assumiu definitivamente o seu lugar como artista e intelectual consagrado no teatro, na televisão e no cinema, após décadas de uma vida inteira dedicada à arte. Os mais variados aspectos dos caminhos trilhados por Fagundes são objeto da detalhada análise empreendida por Rosangela Patriota que, entre diversos elementos, destaca: a passagem de Fagundes pelo Teatro de Arena, a sua presença no campo da cultura de oposição à Ditadura Militar e a entrada do ator no universo da televisão e do cinema, fato esse que acabou por levar a um redimensionamento na carreira de Fagundes ao final dos anos 1970, pois o mesmo passou a contar com um público cada vez maior e alcançou o status de "galã". Ao tratar do trabalho de Fagundes na telenovela Dancin' Days (Gilberto Braga; direção de Daniel Filho, Gonzaga Blota, Marcos Paulo e Dennis Carvalho; codireção: José Carlos Pieri), produzida e exibida pela Rede Globo de Televisão entre julho de 1978 e janeiro de 1979, Patriota afirma:

Fagundes soube agregar ao seu trabalho a sensibilidade de um homem em situação de fragilidade, mas com capacidade imensa de amar, despido dos valores e dos preconceitos de seu segmento de origem. Uma personagem que publicizou os seus sentimentos e sofreu com a rejeição e com o ciúme. Enfim, era um galã sensível que, à sua maneira, preenchia os sonhos de Júlia Matos [personagem interpretada pela atriz Sônia Braga], ao mesmo tempo que atualizava a ideia do homem ideal, em situações que não se resumiam apenas aos conflitos entre o mocinho rico e a mocinha pobre. As barreiras não eram apenas econômicas, elas se apresentavam em níveis culturais, morais e sociais. Porém, mais que isso: ele recuperava Júlia Matos para a felicidade e também era salvo por ela. Sem sombra de dúvida, esse foi um elemento diferencial. Foi a consagração! Antonio Fagundes tornava-se, assim, um dos homens mais assediados do país. De fato, nascia um galã que, pela força interpretativa do ator e pela sutileza da construção dramática do autor, estava sintonizado com as demandas simbólicas do Brasil em embates pela anistia política, pela redemocratização, pela reorganização dos movimentos populares e por novos anseios no que se refere aos costumes e às práticas sociais. ${ }^{7}$

Aqui, Patriota coloca em destaque esse momento muito específico da carreira de Antonio Fagundes na televisão para relembrar que, embora o ator tenha conquistado um espaço importante na maior emissora de TV do país, isso não fez com que Fagundes deixasse de ser o que sempre foi: "um homem de teatro, formado nas discussões do

PATRIOTA, Rosangela. Antonio Fagundes no palco da história: um ator. São Paulo: Perspectiva, 2018, p. 142. 


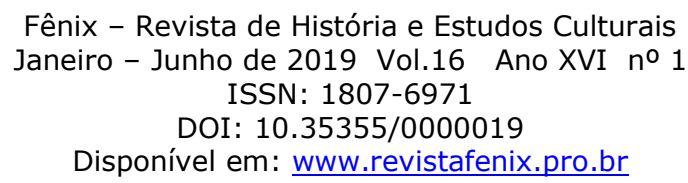

Teatro de Arena de São Paulo", para quem "ser ator é um ofício, uma profissão" e uma forma de inserção "no mundo e no mercado de trabalho", tendo para isso participado de "projetos que estabeleceram níveis de conexão com o público, em geral, e com críticos, em particular". ${ }^{8}$ Dessa maneira, Patriota salienta que, paralelamente ao sucesso obtido na TV, Fagundes deu continuidade ao seu trabalho nos palcos, não apenas como ator, mas também como produtor, algo que ganhou uma forma mais consistente sobretudo a partir da década de 1980, quando Antonio Fagundes criou a Companhia Estável de Repertório (CER).

Rosangela Patriota dedicou um capítulo inteiro do livro ao trabalho de Fagundes dentro da CER, no qual a autora aborda as condições de produção dos espetáculos encenados pela companhia ao longo dos anos $1980,{ }^{9}$ a recepção que as peças tiveram por parte da crítica especializada e também a construção do diálogo palco/plateia dentro das realizações da CER. A análise empreendida por Patriota leva em consideração tanto os aspectos formais dos textos que foram encenados quanto os aspectos das montagens em si, salientando as escolhas que foram feitas pelos diretores e produtores. No que concerne à recepção dos espetáculos por parte da crítica especializada, a autora constrói a sua análise não somente com base no que foi publicado nos jornais da época, mas também em depoimentos dos profissionais envolvidos nas produções da CER, o que faz com que a autora tenha condições de não ficar presa às interpretações que os críticos profissionais fizeram dos espetáculos.

Por sua vez, o diálogo palco/plateia construído pela Companhia Estável de Repertório é um dos principais elementos explorados por Rosangela Patriota, uma vez que, segundo a autora, "para Antonio Fagundes a interlocução com o público em momento algum pode ser negligenciada". ${ }^{10}$ No caso da montagem de Fragmentos de um

8 PATRIOTA, Rosangela. Antonio Fagundes no palco da história: um ator. São Paulo: Perspectiva, 2018, p. 143.

9 Durante o período em que esteve em atividade, a Companhia Estável de Repertório realizou as seguintes montagens: O Homem Elefante (de Bernard Pomerance, 1981, direção de Paulo Autran), Morte Acidental de um Anarquista (de Dario Fo, 1982, direção de Antônio Abujamra), Xandu Quaresma (de Chico de Assis, 1984, direção de Adriano Stuart), Cyrano de Bergerac (de Edmond Rostand, 1985, direção de Flávio Rangel), Carmem com Filtro (de Daniela e Gerald Thomas, 1986, direção de Gerald Thomas), Nostradamus (de Doc Comparato, 1986, direção de Antônio Abujamra), Fragmentos de um Discurso Amoroso (de Roland Barthes, 1988, direção de Ulysses Cruz), O País dos Elefantes (de Louis Charles Sirjacq, 1989, direção de Alain Millianti) e Muro de Arrimo (de Carlos Queiroz Telles, 1990, direção de Antônio Abujamra).

${ }^{10}$ PATRIOTA, Rosangela. Antonio Fagundes no palco da história: um ator. São Paulo: Perspectiva, 2018, p. 259. 
Discurso Amoroso (de Roland Barthes, 1988, direção de Ulysses Cruz), por exemplo, Patriota chama a atenção para o fato de que a CER mantinha um cadastro com os dados dos espectadores dos espetáculos, de modo que a Companhia informou parte do público sobre as datas e horários de realização dos ensaios de Fragmentos de um Discurso Amoroso. Dessa maneira, a CER realizava ensaios abertos ao público, ao final dos quais havia um debate entre os profissionais envolvidos na realização da montagem e a plateia ali presente. Segundo Antonio Fagundes, em depoimento citado por Patriota no livro:

Nós fazíamos uma abertura com a plateia, falando o que tínhamos trabalhado durante a semana. Era uma vez por semana. Aí fazia um ensaio de uma hora, eles quietinhos. Ninguém podia rir, não podia nada. Eu proibia tudo, depois na última meia hora, nós abríamos a discussão com eles. Foi maravilhoso! Interferiu no nosso processo de uma forma muito positiva e, na cabeça deles, foi uma formação. [...] Era público mesmo, não constituíam um grupo de teatro. Dentre eles, tinham bancário, dona de casa, funcionária pública etc... Reuniram-se ali porque estavam cadastrados na companhia. ${ }^{11}$

A preocupação com a efetivação do diálogo palco/plateia dentro das realizações da CER, bem como os aspectos estéticos das produções levadas aos palcos pela Companhia, são elementos que, da perspectiva adotada por Rosangela Patriota, certamente fazem com que o período em que Antonio Fagundes esteve envolvido com a Companhia Estável de Repertório possa ser considerado como um dos mais frutíferos da carreira do ator. Ademais, as reflexões feitas por Patriota a respeito dos trabalhos realizados no âmbito da CER são interessantes na medida em que elas materializam a postura teórico-metodológica da autora já descrita anteriormente, segundo a qual "o tempo não é apreendido da mesma forma por sujeitos e esferas sociais distintos”. Ora, se do ponto de vista da economia a década de 1980 entrou para a História do Brasil com o rótulo de "década perdida", a trajetória de Antonio Fagundes mostra que, para o campo da cultura, tal época não foi "perdida", uma vez que foi durante esse período que se concretizou uma experiência tão singular na cena teatral brasileira como o conjunto de atividades da Companhia Estável de Repertório.

Em uma época na qual se vivenciava o processo de redemocratização do Brasil - quando algumas pessoas ligadas ao teatro produzido nos tempos da Ditadura (dentro

11 FAGUNDES, Antonio apud PATRIOTA, Rosangela. Antonio Fagundes no palco da história: um ator. São Paulo: Perspectiva, 2018, p. 260. 
da "cultura de oposição") pareciam não ter mais espaço em meio às novas demandas sociais, políticas e econômicas que surgiam -, Antonio Fagundes - que era um ator cuja trajetória tinha passado justamente pelo "teatro de resistência" - soube redimensionar suas atividades dentro do novo contexto sem, porém, abrir mão de enfrentar temas e questões que o interessavam desde os anos 1960 e 1970. A atuação de Fagundes na CER é um dos marcos da especificidade da trajetória do Antonio Fagundes, um ator/produtor que, embora tivesse a mesma idade de outros atores/produtores que também estavam em atividade nos anos 1980, tinha até ali uma trajetória muito particular, sobretudo em função do fato de ele ter iniciado as suas atividades artísticas na década de 1960, quando entrou em contato com diversos atores, dramaturgos e produtores que já agitavam a cena teatral brasileira.

Um outro aspecto importante da trajetória de Fagundes que ganha bastante espaço nas páginas de Antonio Fagundes no palco da história: um ator é o fato de este artista não ter entrado em uma "zona de conforto" após alcançar o sucesso na televisão, no cinema e no teatro. Como Rosangela Patriota mostra, a partir dos anos dos 1990, Fagundes continuou trabalhando em um ritmo bastante intenso, envolvendo-se nos mais variados projetos e utilizando a sua arte para tratar dos mais variados temas. Apenas para citar alguns exemplos lembrados pela autora, no cinema Fagundes trabalhou em filmes como Fica Comigo (1995, de Tizuka Yamasaki e Jorge Duran), Doces Poderes (1996, de Lúcia Murat), O Tronco (1998, de João Batista de Andrade), Deus é Brasileiro (2001, de Cacá Diegues), Achados e Perdidos (2005, de José Joffily), Quando Eu Era Vivo (2012, de Marcos Dutra) e Alemão (2014, de José Eduardo Belmonte).

$\mathrm{Na}$ televisão, Fagundes interpretou papéis em telenovelas como Rainha da Sucata (1990), O Dono do Mundo (1991), Renascer (1993), A Viagem (1994), O Rei do Gado (1996), Por Amor (1997), Terra Nostra (1999), Porto dos Milagres (2001), Duas Caras (2007), Insensato Coração (2011), Meu Pedacinho de Chão (2014) e Velho Chico (2016), além de seriados e minisséries como Você Decide (1992), Comédia da Vida Privada (1995), Brava Gente (2002), Carga Pesada (2003-2007), Mad Maria (2005) e Dois Irmãos (2017).

É preciso dizer que Antonio Fagundes participou dessas e de tantas outras produções no cinema e na TV sem nunca perder o teatro de vista. Nas últimas décadas, 
o ator e produtor se envolveu na montagem dos mais variados espetáculos, tais como Macbeth (de William Shakespeare, 1992), Vida Privada (de Mara Carvalho, 1994), Oleanna (de David Mamet, 1995), Últimas Luas (de Furio Bordon, 1999), Sete Minutos (do próprio Antonio Fagundes, 2002), Mulheres da Minha Vida (de Neil Simon, 2005), Restos (de Neil Labute, 2009), Vermelho (de John Logan, 2012) e Tribos (de Nina Raine, 2013).

Como se vê, o protagonista da narrativa elaborada por Rosangela Patriota tem uma trajetória bastante consistente na televisão, no cinema e no teatro. E a autora de Antonio Fagundes no palco da história: um ator explora os muitos detalhes da carreira de Fagundes, oferecendo ao leitor refinadas análises dos personagens interpretados por Antonio Fagundes ao longo dos anos, além de reflexões sobre como o trabalho do ator foi percebido pela crítica especializada. Como se não bastasse todo o esforço empreendido por Patriota para oferecer ao leitor a maior inteligibilidade possível sobre o percurso artístico, intelectual e profissional de Fagundes, a autora ainda apresenta uma série de reflexões muito interessantes acerca do mercado de bens simbólicos, do diálogo palco/plateia e da própria historiografia do Teatro Brasileiro, mobilizando para isso uma série de documentos históricos e referências bibliográficas.

No que tange especificamente à historiografia do Teatro Brasileiro, um mérito inegável do livro é que a obra demonstra o quanto a dicotomia entre "teatro comercial" e "teatro de ideias" é um falso problema, pois, como os trabalhos realizados por Fagundes nos palcos nos mostram, o teatro pode ser ao mesmo tempo "comercial" e também “de ideias". Além disso, ao colocar o ator no centro das reflexões sobre teatro, Antonio Fagundes no palco da história: um ator dá uma contribuição interessante para a escrita da História do Teatro Brasileiro, uma vez que a questão do trabalho do ator muitas vezes fica em segundo plano nos livros sobre teatro, que muitas vezes focam no trabalho dos dramaturgos e na realização propriamente dita dos espetáculos. Ao voltarse para o trabalho de quem está efetivamente no palco, Rosangela Patriota revela o quanto é capaz de olhar - com os "olhos livres" - para onde muitos ainda não olharam com a devida atenção.

Pelas informações que traz, pelas ideias que guiam a narrativa e pela grande variedade de reflexões que consegue provocar, o novo livro de Rosangela Patriota é absolutamente imperdível. A obra trata de assuntos muito complexos de maneira 
simples e acessível, e há momentos em que a autora "quebra" o fluxo da narrativa para conversar com o leitor, elaborando um texto cheio de idas e vindas que tornam o livro ainda mais surpreendente a cada página.

A sensação que se tem ao ler Antonio Fagundes no palco da história: um ator é comparável à sensação que se tem ao observar uma pintura impressionista. Como se sabe, quando olhamos este tipo de obra de arte a partir de uma certa distância, somos capazes de reconhecer várias formas e figuras, todavia, à medida em que vamos nos aproximando do quadro, tais formas e figuras vão aos poucos "se desfazendo" diante dos nossos olhos, dando lugar a uma infinidade de traços e minúsculos pontos que até então éramos incapazes de ver. É justamente essa sensação que o livro proporciona ao leitor quando trata do teatro no Brasil. Ora, vista a partir de uma certa distância, a História do Teatro Brasileiro é marcada por diversos temas já consagrados - a "modernização", o "nacionalismo crítico", o "teatro de resistência", etc. -, as "ideiasforça" que orientam as interpretações sobre a cena teatral brasileira em diversos períodos. ${ }^{12}$ Porém, ao eleger para a análise um tema não tão consagrado dentro da historiografia - como a trajetória de um ator/produtor como Antonio Fagundes -, e ao "aproximar-se" de tal tema de maneira criteriosa, Rosangela Patriota proporciona ao leitor a oportunidade de enxergar inúmeros detalhes sobre o Teatro Brasileiro que muitos sequer imaginavam que existiam dentro da História. Libertando-se dos temas já consagrados no âmbito da historiografia, Patriota logra êxito em demonstrar no seu livro o quanto de "diversidade" existe nos palcos do país.

Por estimular tantas reflexões e proporcionar uma agradável leitura, Antonio Fagundes no palco da história: um ator merece estar na biblioteca de todos aqueles que se interessam pela cultura brasileira.

Assim, só nos resta desejar a todos uma excelente leitura!

12 Para mais detalhes sobre essas "ideias-força" que balizam muitas das reflexões sobre o teatro no Brasil, ver: PATRIOTA, Rosangela; GUINSBURG, Jacó: Teatro Brasileiro: ideias de uma história. São Paulo: Perspectiva, 2012. 269p. 

ISSN: $1807-6971$

DOI: $10.35355 / 0000019$

Disponível em: www.revistafenix.pro.br 